\title{
Food Security among the Elderly: An Area of Concern \\ Paramita Sengupta
}

Department of Community Medicine, Christian Medical College and Hospital, India

*Corresponding author: Paramita Sengupta, Christian Medical College and Hospital Ludhiana, Ludhiana, India, Tel: 04162282010; E-mail:

drparamita2425@gmail.com

Rec date: Jun 17, 2016; Acc date: Jun 28, 2016; Pub date: Jul 02, 2016

Copyright: ( 2016 Sengupta P. This is an open-access article distributed under the terms of the Creative Commons Attribution License, which permits unrestricted use, distribution, and reproduction in any medium, provided the original author and source are credited.

\section{Short Communication}

A new report conducted by the US Census Bureau and the national institute of aging (NIA) estimates the current elderly population to double by 2050 [1]. People are living longer, which does not necessarily mean that they are living healthier $[1,2]$. Healthy ageing is associated with a number of physiological, cognitive, social and lifestyle changes that influence dietary intakes and nutritional status. Health status is closely related to the ageing process, nutrition playing an important role on the rate of the ageing process [3].

Food security encompasses the ready availability of nutritionally adequate and safe food for an active, healthy life [4]. The concept of food security is defined as including both physical and economic access to food that meets people's dietary needs as well as their food preferences. In 2009, the World Summit on Food Security stated that the "four pillars of food security are availability, access, utilization, and stability" [5] wherein food availability is provision of sufficient quantities of food of appropriate quality, through domestic production or imports; food access implies access by individuals to adequate resources for acquiring appropriate foods for a nutritious diet; food utilization through adequate diet, clean water, sanitation and health care to reach a state of nutritional well-being where all physiological needs are met; and food stability ensures access to adequate food at all times by individual/household.

Food insecurity is characterized by "limited access to or availability of nutritionally-adequate, culturally relevant, and safe food and/or limited or uncertain ability to acquire food in socially acceptable ways [6]. Food insecurity represents a major public-health concern and is a useful index of health and wellbeing because it is associated with poverty, ill-health, poor dietary intake (e.g. low intake of fruits and vegetables), limited social capital, and depressive disorders [7].

Inadequate income is an established cause of inadequate food intake and a cause for concern in some older adults [8]. The elderly are at increased risk of both infections and death from infections, including foodborne illnesses, as a result of a decrease in immune function, chronic diseases and factors such as malnutrition [9]. Food insecurity in older adults is a multidimensional phenomenon and is associated with numerous unfavorable nutrition- and non-nutrition related outcomes that may affect the health and well-being of the older population [10]. It has been shown to negatively impact, directly and indirectly, an individual's health status and quality of life [11].

The experience of food insecurity in the elderly has four components: quantitative, qualitative, psychological and social with inability to obtain right foods for health, an element specific to marginalized population such as older persons [12]. Food insecurity in elderly persons comprises not only limited food affordability, availability, and accessibility but also altered food use.
The household food security survey module (HFSSM) is a reasonable way to assess food insecurity in older adults [13]. The food security status of the elderly is analyzed on the modified 6-item HFSSM (score 0-6). The sum of affirmative responses is calculated and used to classify the individual into 1 of 4 levels of food security [food security (score 0 ), marginal food security (score 1), low food security (score 2-4), and very low food security (score 5-6)]. It is then categorized as food secure (score 0-1) and food insecure (score 2-6).

Food-insecure elderly persons experience multiple problems that prevent them from achieving nutritional well-being and seeking food assistance programs. Given that many elders already experience waning health and have more health and nutritional needs than the general population, food insecurity may exacerbate existing health complications in addition to added emotional and economic distress [14].

Nutrition services should recognize and provide services to cover those needs. Nutrition security that includes food security as well as other factors affecting nutrition maybe a more useful framework for assessing and inter-relating the range of issues that affect nutritional adequacy of diets of the elderly [15]. Adequate preventive measures and treatment strategies for the elderly at risk of malnutrition. A comprehensive, multidisciplinary approach is often helpful in addressing all contributing factors in the treatment of compromised nutritional health in the elderly [16].

\section{References}

1. He W, Goodkind D, Kowal P (2015) An Aging World: 2015. International Population Reports. United States Census Bereau. Accessed on July 12, 2016.

2. Cire B. World's older population grows dramatically. NIH-funded Census Bureau report offers details of global aging phenomenon. U.S. Department of Health \& Human Services.Accessed on March 28, 2016.

3. http://apps.who.int/iris/bitstream/10665/42515/1/9241562102.pdf

4. Definitions of Food Security (2015) Visit USDA's Economic Research Service United States Department of Agriculture: Economic Research Service. Accessed on July 12, 2016.

5. http://www.fao.org/docrep/meeting/029/MI019e.pdf

6. Barrett P, Twitchin S, Kletchko S, Ryan F (2006) The living environments of community-dwelling older people who become frail: another look at the living standards of older New Zealanders survey. Social Policy Journal of New Zealand 28: 133-157.

7. http://www.fao.org/docrep/003/w3613e/w3613e00.HTM

8. Hadley C, Zodhiates A, Sellen DW (2007) Acculturation, economics and food insecurity among refugees resettled in the USA: a case study of West African refugees. Public Health Nutr 10: 405-412.

9. Kendall P, Van Hiller V, Medeiros L (2006) Food safety guidance for older adults. Aging and Infectious Diseases 42: 1298-1304. 
Citation: Sengupta P (2016) Food Security among the Elderly: An Area of Concern. J Gerontol Geriatr Res 5: 320 . doi: $10.4172 / 2167-7182.1000320$

Page 2 of 2

10. Lee JS, Fischer JG, Johnson MA (2010) Food insecurity, food and nutrition programs, and aging: experiences from Georgia. Nutr Elder 29: 116-149.

11. Stuff J E, Patrick HC, Szeto KL, Gossett JM, Robbing JM, et al. (2004) Household Food Insecurity is Associated with Adult Health Status. J Nutr 134: $2330-2335$

12. Wolfe WS, Frongillo EA, Valois P (2003) Understanding the Experience of Food Insecurity by Elders Suggests Ways to Improve Its Measurement. J Nutr 133: 2762-2769.

13. Lee JS, Johnson MA, Brown A, Nord M (2011) Food security of older adults requesting older Americans Act Nutrition Program in Georgia can be validly measured using a short form of the U.S household Food Security Survey Module. J Nutr 141: 1362-1368.

14. Lee JS, Frongillo EA (2001) Factors Associated with Food Insecurity among U.S. Elderly Persons: Importance of Functional Impairments. J Gerontol 56: S94-S99.

15. Garret JL, Ruel MT (2000) Achieving urban food and nutrition security in the developing world. Washington DC. International Food Policy Research Institute (IFPRI) 3: 1-2.

16. Wells JL, Dumbrell AC (2006) Nutrition and Aging: Assessment and Treatment of Compromised Nutritional Status in Frail Elderly Patients. Clinical Interventions in Aging 1: 67-79. 